\title{
The Antecedents and Consequences of Occupation Dissatisfaction for Technical R\&D Personnel - test of the lower-level demand hypothesis
}

\author{
Yiqi Yang ${ }^{1, a, *}$, Hong $\mathrm{Li}^{2, \mathrm{~b}}$ \\ ${ }^{1}$ School of Economics and Management, Nanjing University of Science and Technology, Nanjing \\ 210000,China; \\ ${ }^{2}$ School of Economics and Management, Nanjing University of Science and Technology, Nanjing \\ 210000, China. \\ a578286645@qq.com, b1804445023@qq.com
}

Keywords: Technical R\&D personnel, Occupation dissatisfaction, Low-level demand, High-level demand, Career shift tendency.

\begin{abstract}
The results showed that: (1) currently the main workplace dissatisfaction of technical R\&D personnel in China are "low income", "low occupational security", "lack of organizational support" and "lack of respect and social status". The factor loading of "income" and "occupational security" are the highest, this means that the low-level demand of China technical R\&D personnel are not satisfied, leading to the occupation dissatisfaction, and thus significantly affect the career shift tendency.(2) and in the analysis of the relationship between occupation dissatisfaction and career shift tendency, the significant adjustment of low-level demand is tested.
\end{abstract}

\section{Introduction}

The motivation of this research is from an economic forum in China:"do you plan to eat by technology?". Discussion shows that the technology professionals have common occupation dissatisfaction and strong career shift tendency. Most of the dissatisfaction is related to income and occupational security, this shows that low-level demand of the research and development personnel have not been effectively met. This finding does not correspond with many existing studies.

Our study takes the technical R\&D personnel as the objects, explores the relationship between occupation dissatisfaction, demand level and career shift tendency of technical R\&D personnel in the China, and seeks to find some effective measures to improve their occupation satisfaction.

\section{Theoretical Basis and Hypotheses}

\subsection{Job Dissatisfaction and Occupation Dissatisfaction}

Existing research has found that the relationship between job satisfaction and employee performance is complex, and many seemingly established assumptions are not supported by empirical data[1]. Some scholars have turned to the opposite of job satisfaction - job dissatisfaction in the study. Farrell is one of the most prominent scholars in this research field. His research focused on the possible responses and action taken by the dissatisfied employees and he proposed the famous EVLN model[2]. In the case of job dissatisfaction studies, we propose the occupation dissatisfaction and define it as the negative feelings of a certain type of professional in the profession. It is the general attitude of the individual for a particular occupation. 


\subsection{Career Shift Tendency}

This study focuses on a more common response that may be triggered by dissatisfaction withdrawal behavior or willingness, that is, the behavior or willingness of employees to leave their former company or profession and find new jobs. This paper proposes career shift tendency to express the possibility and intention of an employee shifting from one career area to another.

\section{Research Method}

\subsection{Research Hypothesis}

This study presents the following two hypotheses on the basis of three research variables: the level of demand, occupation dissatisfaction and career shift tendency.

Hypothesis 1: the occupation dissatisfaction of technical $R \& D$ personnel is significantly positively correlated with career shift tendency.

Hypothesis 2: the demand level of the technical R\&D personnel is significantly positively correlated with occupation dissatisfaction.

In addition, this study also examined the impacts of low-level demand and high-level demand on the relationship between occupation dissatisfaction and career shift tendency. Therefore, we propose the following hypotheses:

Hypothesis 3: compared with the high-level demand, the technical R\&D personnel have a stronger low-level demand.

Hypothesis 4: compared with the high-level demand, the low-level demand of technical R\&D personnel has a stronger positive correlation with occupation dissatisfaction.

Hypothesis 5: compared with the high-level demand, the low-level demand of technical R\&D personnel has a stronger moderating effect on the relationship between occupation dissatisfaction and career shift tendency.

According to the existing literature[3], this study selected gender, length of service, education, job position, technical career years, the nature of the company and the industry as the control variables.

\subsection{Variables Measurement and Data Processing and Analysis}

The occupation dissatisfaction questionnaire was compiled based on in-depth interviews with the technical R\&D personnel. It consists of 23 items, including technical occupation attributes, salary benefits, occupational security, status, resources, organizational support and so on. The demand level questionnaire was taken from the Maslow demand hierarchy scale of Mitchell et al.(1976), with 24 items in total. The career shift tendency questionnaire was adopted by Carson et al. (1994), according to the actual situation of China, we revised the scale, including 4 items.

This study used SPSS20.0 as the analysis tool, including validity and reliability analysis, correlation analysis and regression analysis.

\section{The Quantitative Analysis}

\subsection{Sample Background Analysis}

In this study, we selected on-the-job technical $R \& D$ personnel with an engineering background as the subjects. In total 328 questionnaires were issued, all of the invalid questionnaires were deleted. In the last, there were 251 valid questionnaires, and the recovery rate of the valid questionnaires was $76.52 \%$. This study has a wide range of samples, and the subjects are well represented.

\subsection{Validity and Reliability Analysis}

The results of structural validity of the demand level, occupation dissatisfaction, and career shift tendency indicate that the data is suitable for factor analysis(KMO>0.7). According to the research design, two common factors are extracted from the demand level. Four common factors are extracted from the occupation dissatisfaction, respectively status and development, network and achievement, occupational security and occupational cost. Career shift tendency extract one common factor. Since all the scales have been revised, the reliability of Cronbach 'alpha should be tested. The reliability analysis shows that, in addition to the occupational cost scale, the Cronbach 'alpha coefficient of the 
remaining scales is bigger than the 0.70 standard recommended by Nunnally (1978), the Cronbach 'alpha coefficient of occupational cost scale is 0.683 , reaching the minimum acceptable value standard put forward by the scholar DeVellis.

\subsection{Correlation Analysis}

Table 1 summarizes the average, standard deviation and correlation coefficients of the variables. As can be seen from table 1, there is a significant positive correlation between the level of demand and occupation dissatisfaction of the technical $R \& D$ personnel $(r=0.248, p<0.01)$, occupation dissatisfaction is also positively correlated with career shift tendency $(\mathrm{r}=0.199, \mathrm{p}<0.01)$. That supports hypothesis 1 and hypothesis 2 . At the same time, the positive correlation between low-level demand and occupation dissatisfaction $(\mathrm{P}<0.01)$ is significantly stronger than the positive correlation between high-level demand and occupation dissatisfaction $(\mathrm{P}<0.05)$, thus hypothesis 4 is supported.

Table 1 Descriptive Statistics and Correlations ${ }^{\text {a }}$

\begin{tabular}{|l|c|c|c|c|c|c|c|}
\hline \multicolumn{1}{|c|}{ Variables } & Mean & s.d. & 1 & 2 & 3 & 4 & 5 \\
\hline 1 Demand level & 3.599 & .380 & 1 & & & & \\
\hline 2 Low-level demand & 3.967 & .496 & $.424^{* *}$ & 1 & & & \\
\hline 3 High-level demand & 3.416 & .516 & $.900^{* *}$ & -.013 & 1 & & \\
\hline 4 Occupation dissatisfaction & 3.109 & .596 & $.248^{* *}$ & $.301^{* *}$ & $.129^{*}$ & 1 & \\
\hline 5 Career shift tendency & 3.211 & .845 & .059 & -.015 & .073 & $.199^{* *}$ & 1 \\
\hline
\end{tabular}

${ }^{\mathrm{a}} \mathrm{n}=251, * \mathrm{p}<0.05, * * \mathrm{p}<0.01$

\subsection{Hypothesis Testing Analysis}

The descriptive statistics results of low-level demand and high-level demand of technical R\&D personnel show that (low-level demand and high-level demand are obtained by the means of the average score of all items in each sample), the mean value of low-level demand for technical R\&D personnel is 3.967, higher than the mean of its high-level demand (3.416), which indicates that the low-level demand of technical R\&D personnel in general is stronger than that of high-level demand. At the same time, by comparing the difference between the low-level demand and the high-level demand, we found that about $79.68 \%$ of the respondents in the survey had higher scores on the low-level demand than the high-level demand, which on the other hand shows that the low-level demand of technical R\&D personnel is stronger than the high-level demand. Through the above analysis, hypothesis 3 is verified.

We use multiple regression analysis to test hypothesis 5. First of all, it is important to verify the moderating effect of low-level demand of technical $R \& D$ personnel on the relationship between occupation dissatisfaction and career shift tendency. The results are shown in table 2 . According to the results, when the low-level demand is measured, the relationship between occupation dissatisfaction and career shift tendency is more significant. According to the data in the table 2, the low-level demand of the technical $\mathrm{R} \& \mathrm{D}$ personnel has a moderating effect on the relationship between occupation dissatisfaction and career shift tendency $(\mathrm{P}<0.01)$, that is, the low-level demand enhances the positive effect of occupation dissatisfaction on career shift tendency. This means that in China the strong career shift tendency of technical R\&D personnel mainly stem from the strong low-level demand failed to be met. Second, it is important to verify the adjustment function of the high-level demand of technical $R \& D$ personnel on the relationship between occupation dissatisfaction and career shift tendency. The results are shown in Table 3. According to Table 3, we find that the high-level demand of technical R\&D personnel has no moderating effect on the relationship between occupation dissatisfaction and career shift tendency $(\mathrm{P}>0.05)$. Based on the above, it is assumed that hypothesis 5 is partially verified.

\section{Conclusions}

The occupation dissatisfaction of technical R\&D personnel is significantly positively correlated with career shift tendency. It is explained that high occupation dissatisfaction is the reason for the strong career shift tendency of technical R\&D personnel. Therefore, companies should pay more attention to the low-level demand of technical R\&D personnel, such as the design of a more 
reasonable pay and benefits system, to provide employees with appropriate training and help them to develop a reasonable career planning to reduce their occupation dissatisfaction.

There is also a significant positive correlation between the level of demand for technical R\&D personnel and occupation dissatisfaction. Through further analysis, it is found that the correlation between low-level demand and occupation dissatisfaction is more obvious, which indicates that the strong low-level demand is not satisfied, which is the main reason for the occupation dissatisfaction of technical R\&D personnel.

Low-level demand for technical R\&D personnel is stronger than high-level demand. Different from previous research findings, this study found that relative to the high-level demand, technical R\&D personnel have a stronger low-level demand, these low-level demand factors include income, occupational safety and so on.

Table 2 Regression analysis of low-level demand regulation

\begin{tabular}{|c|c|c|c|c|c|c|c|c|c|}
\hline & \multicolumn{3}{|c|}{ Model 1} & \multicolumn{3}{|c|}{ Model 2} & \multicolumn{3}{|c|}{ Model 3} \\
\hline & B & $\beta$ & $\mathrm{P}$ & B & $\beta$ & $\mathrm{P}$ & B & $\beta$ & $\mathrm{P}$ \\
\hline (Constant) & 2.856 & & .000 & 2.025 & & .000 & 1.922 & & .000 \\
\hline Gender & .125 & .062 & .331 & .129 & .065 & .306 & .160 & .080 & .199 \\
\hline Length of service & .008 & .011 & .927 & .011 & .015 & .895 & -.041 & -.058 & .624 \\
\hline Technical occupation years & -.022 & -.029 & .802 & -.015 & -.019 & .863 & .035 & .044 & .697 \\
\hline Job position & .062 & .057 & .442 & .081 & .075 & .310 & .113 & .104 & .157 \\
\hline The nature of the company & .077 & .095 & .169 & .035 & .043 & .536 & .014 & .017 & .806 \\
\hline Industry & .088 & .123 & .058 & .084 & .118 & .064 & .078 & .109 & .082 \\
\hline Education & -.091 & -.064 & .340 & -.078 & -.054 & .412 & -.077 & -.054 & .406 \\
\hline Occupation dissatisfaction & & & & .269 & .190 & .004 & .280 & .197 & .002 \\
\hline $\begin{array}{c}\text { Occupation } \\
\text { dissatisfaction } \times \text { low-level } \\
\text { demand }\end{array}$ & & & & & & & .543 & .187 & .004 \\
\hline $\bar{F}$ & \multicolumn{3}{|c|}{1.279} & \multicolumn{3}{|c|}{2.232} & \multicolumn{3}{|c|}{3.005} \\
\hline Adjusted $\mathrm{R}^{2}$ & \multicolumn{3}{|c|}{.008} & \multicolumn{3}{|c|}{.038} & \multicolumn{3}{|c|}{.067} \\
\hline$\Delta \mathrm{R}^{2}$ & \multicolumn{3}{|c|}{.036} & \multicolumn{3}{|c|}{.033} & \multicolumn{3}{|c|}{.032} \\
\hline
\end{tabular}

Table 3 Regression analysis of high-level demand regulation

\begin{tabular}{|c|c|c|c|c|c|c|c|c|c|}
\hline & \multicolumn{3}{|c|}{ Model 1} & \multicolumn{3}{|c|}{ Model 2} & \multicolumn{3}{|c|}{ Model 3} \\
\hline & $\mathrm{B}$ & $\beta$ & $\mathrm{P}$ & $\mathrm{B}$ & $\beta$ & $\mathrm{P}$ & $\mathrm{B}$ & $\beta$ & $\mathrm{P}$ \\
\hline (Constant) & 2.856 & 2.856 & .000 & 2.025 & & .000 & 2.008 & & .000 \\
\hline Gender & .125 & .125 & .331 & .129 & .065 & .306 & .142 & .071 & .262 \\
\hline Length of service & .008 & .008 & .927 & .011 & .015 & .895 & .011 & .015 & .896 \\
\hline Technical occupation years & -.022 & -.022 & .802 & -.015 & -.019 & .863 & -.008 & -.010 & .927 \\
\hline Job position & .062 & .062 & .442 & .081 & .075 & .310 & .078 & .072 & .330 \\
\hline The nature of the company & .077 & .077 & .169 & .035 & .043 & .536 & .032 & .040 & .572 \\
\hline Industry & .088 & .088 & .058 & .084 & .118 & .064 & .083 & .116 & .068 \\
\hline Education & -.091 & -.091 & .340 & -.078 & -.054 & .412 & -.078 & -.054 & .412 \\
\hline Occupation dissatisfaction & & & & .269 & .190 & .004 & .271 & .191 & .003 \\
\hline $\begin{array}{c}\text { Occupation } \\
\text { dissatisfaction } \times \text { low-level } \\
\text { demand } \\
\end{array}$ & & & & & & & -.173 & -.060 & .342 \\
\hline$F$ & \multicolumn{3}{|c|}{1.279} & \multicolumn{3}{|c|}{2.232} & \multicolumn{3}{|c|}{2.084} \\
\hline Adjusted $\mathrm{R}^{2}$ & \multicolumn{3}{|c|}{.008} & \multicolumn{3}{|c|}{.038} & \multicolumn{3}{|c|}{.038} \\
\hline$\Delta \mathrm{R}^{2}$ & \multicolumn{3}{|c|}{.036} & \multicolumn{3}{|c|}{.033} & \multicolumn{3}{|c|}{.003} \\
\hline
\end{tabular}

The low-level demand has a significant impact on the relationship between occupation dissatisfaction and career shift tendency, while the high-level demand has no effect on the 
relationship between job dissatisfaction and career shift tendency. Therefore, we conclude that high-level demand is not the cause of technical R\&D personnel's strong career shift tendency.

\section{References}

[1] Shangkun Xu. 2007. Research Progress of Job Dissatisfaction and Employee Creativity. Foreign Economy and Management 29(8):38-44.

[2] Dan, F. 1983. "Exit, Voice, Loyalty, and Neglect as Responses to Job Dissatisfaction: A Multidimensional Scaling Study”. Academy of Management Journal 26(4):596-607.

[3] Kerlinger, F. N. \& Lee, H. B. 2000. Foundations of behavioral research (4th Ed.). New York, NY: Holt, Rinehart and Winst. 